Research Article

\title{
Study on Green Supply Chain Cooperation and Carbon Tax Policy considering Consumer's Behavior
}

\author{
Jian Liu (iD) and Chao Hu (iD \\ School of Information Technology, Jiangxi University of Finance and Economics, Nanchang 330032, China \\ Correspondence should be addressed to Chao Hu; hc173067300@163.com
}

Received 23 June 2020; Revised 11 August 2020; Accepted 4 December 2020; Published 29 December 2020

Academic Editor: Rong-Chang Chen

Copyright (C) 2020 Jian Liu and Chao Hu. This is an open access article distributed under the Creative Commons Attribution License, which permits unrestricted use, distribution, and reproduction in any medium, provided the original work is properly cited.

Carbon tax policy has been shown to be an effective incentive for the reduction of carbon emissions, and it also profoundly influences supply chain cooperation. This paper explores the interaction between carbon taxes and green supply chain cooperation. Specifically, we analyze the impact of a carbon tax on green supply chain coordination and further optimize the carbon tax to achieve a win-win situation for both the supply chain and the environment. Because consumer's behavior has a significant impact on green product demand, we consider the problems above under two types of consumer's behavior characteristics: consumer's environmental awareness and consumer's reference behavior. A game-theoretic model is employed to describe a green supply chain consisting of a manufacturer and a retailer, combining important factors such as the carbon tax rate, green investment coefficient, and degree of reference effect. Then, we obtain the optimal carbon tax rate by balancing the total tax revenue and product greenness. A revenue-sharing contract is introduced to achieve green supply chain coordination, and the impact of the carbon tax on coordination is analyzed. The results show the following. (1) The carbon tax rate and the difference between the power of the manufacturer and retailer are the main factors determining green supply chain coordination. (2) Maximum greenness can be achieved when development costs are higher, while the maximum tax revenue is obtained when the development cost is lower, but with the loss of greenness. (3) If the power of the manufacturer is low, coordination can be achieved under the optimal carbon tax. If the power of the manufacturer is at a medium level, coordination can be achieved by increasing the carbon tax; as a result, increased greenness will be realized, but with the loss of tax revenue. However, when the power of the manufacturer is strong, coordination cannot be achieved. (4) Price reference behavior can promote supply chain coordination, but consumer's environmental awareness cannot.

\section{Introduction}

With the degradation of the environment, increasing attention has been directed toward global warming. For sustainable development, many countries have been committed to reducing carbon emissions. For example, at the 2009 United Nations Climate Conference in Copenhagen, the Chinese government declared that carbon dioxide emissions per unit of GDP would be decreased by $40 \%-50 \%$ in 2020 compared with the levels in 2005 [1]. Carbon dioxide is widely emitted by the transportation and manufacturing sectors [2]. Carbon tax policy has been proven to be effective for emissions reduction [3-5], but it also exerts some side effects on enterprises [6]. From the perspective of the green supply chain, carbon tax policies imposed on an enterprise could decrease the profit within the supply chain, thus affecting supply chain cooperation. However, previous research [7-9] has mostly focused on decision-making and cooperation problems within the supply chain under a given carbon tax level, rather than considering the interaction between carbon taxes and supply chain cooperation. Therefore, it is important to examine the interaction between carbon taxes and supply chain cooperation.

Currently, to meet the requirements of carbon tax regulations, a growing number of enterprises have been striving for sustainability by committing to designing, producing, and promoting green products to reduce carbon emissions [10]. In this context, green products have been 
regarded as one of the important factors in achieving economic growth, energy conservation, and environmental sustainability [11]. Benjaafar et al. inferred that introducing carbon emissions into a supply chain optimization models can promote emissions reduction in the supply chain [12]. Meanwhile, carbon taxes increase production costs, thus imposing burdens on enterprises. Consequently, it has been increasingly challenging for governments to enact appropriate policies to reduce carbon emissions and improve supply chain performance at the same time [13]. In addition, consumer's behavior is a crucial factor affecting product demand and sustainable decisions. In this study, we consider two types of consumer's behavior characteristics: consumer environmental awareness (CEA) and consumer's reference behavior. The former is an important factor that motivates firms to develop green products $[14,15]$. The latter is a crucial factor that affects green product demand $[16,17]$. In reality, many enterprises are concerned about carbon emissions, for example, HP, IBM, Ge, etc. They are not only beginning to design green products but also enhancing supply chain management and cooperation to achieve the goal of emission reduction. However, it is hard to achieve supply chain cooperation. Therefore, it is meaningful to study supply chain green decisions and cooperation considering consumer environmental awareness under a carbon tax policy. Therefore, we consider the interaction between the carbon tax rate and supply chain cooperation and optimize the tax rate in the context of CEA and consumer's reference behavior. Specifically, we aim to answer the following questions:

(i) Is carbon tax policy favorable for improving the greenness of products?

(ii) Can carbon tax policy promote supply chain coordination to incentivize supply chain members to cooperate?

(iii) Can carbon tax policy be beneficial for both product greenness and supply chain coordination simultaneously?

To investigate the above problems, a two-echelon supply chain is introduced. This is used to explore the interaction between green supply chain cooperation and carbon tax policy, where a manufacturer acts as the leader and determines the product's greenness and wholesale price, and a retailer acts as the follower and determines the retail price of green products. Moreover, traditional products without green attributes (i.e., greenness) compete with green products in the market. Through consumer utility, we obtain the demand functions for both green and traditional products. In addition, the government decides the carbon tax rate to limit carbon emissions. Unit carbon emissions are associated with the greenness of products. The higher the greenness, the higher the product $R \& D$ cost, and the lower the unit carbon emission. Finally, the impact of the carbon tax on supply chain cooperation is analyzed by introducing a revenue-sharing contract.

The results show the following. (1) When the carbon tax and development cost are at high levels, the greenness increases with the carbon tax; otherwise, the greenness decreases with increasing carbon tax. Therefore, there exists an optimal carbon tax to maximize the greenness when the development cost is high. (2) Cooperation can be promoted when the government increases the carbon tax because the retailer plays a crucial role in coordination, and the region of cooperation is expanded when the carbon tax increases. (3) When the manufacturer's power is relatively low, optimal carbon tax and supply chain cooperation can be achieved simultaneously, whereas when the manufacturer's power is relatively high, cooperation cannot be achieved. In addition, when the manufacturer's power is at a moderate level, cooperation can be achieved but with a loss of tax revenue in such a case.

The main contributions of this paper are as follows. We investigated a green supply chain cooperation problem and the interaction between carbon taxes and supply chain cooperation, taking consumer's reference behavior into consideration, which fills a research gap in supply chain cooperation. Our result provides a reference for pricing and green product design and a meaningful reference for policymakers.

The remainder of this paper is organized as follows. A literature review is presented in Section 2. Section 3 introduces the basic assumptions and notations, and the supply chain model is formulated; then, the results of the model are analyzed, and we summarize the major conclusions of the numerical analysis. Finally, Section 4 summarizes the main research content and results.

\section{Literature Review}

Three streams of research are closely related to our work. First, we review the research on carbon taxes in green supply chains. Second, our work is related to research on reference behaviors in operational management. Third, relevant research on supply chain coordination is reviewed. Finally, we distinguish our study from the three streams of research mentioned above.

2.1. Carbon Tax. Reduction of greenhouse gas emissions is becoming a vital issue, and almost all developed and developing countries are now implementing policies for carbon emission reduction [18]. Numerous studies have focused on carbon taxes. Carbon taxes restrict the demand for fuels and thereby reduce the emissions of harmful greenhouse gases. Generally, carbon taxes are not always as high as possible. For example, a falling tax rate encourages manufacturers to produce and reduce emissions [19]. The optimization problem of carbon taxes has previously been studied [20]. Modak and Kelle integrated corporate social responsibility (CSR) investments into the supply chain strategy and operations and concluded that the optimal recycling rate and appropriate investment in recycling activities increase with an increase in the carbon tax rate [21]. There has also been other research regarding carbon taxes. For example, Ulph and Ulph analyzed the optimal time path for a carbon tax, and the numerical results suggested that a 
carbon tax should initially rise and then fall [22]. Kverndokk considered the optimal extraction of exhaustible resources and came to the same conclusion: the optimal carbon tax should initially rise and eventually fall [23]. Some scholars have suggested that the optimal tax should increase monotonically or follow a U-shaped pattern [24, 25]. However, the above studies did not consider the carbon tax in the context of a supply chain.

There are some research gaps in the studies on optimal carbon taxes for green supply chains. Most of the studies have focused on the decisions and cooperation problems of the supply chain under a carbon tax. Hariga et al. presented three operational models to determine the optimal lotsizing and shipping quantities to reduce carbon emissions. In those experiments, a minor increase in operational cost with carbon tax regulation is outweighed by the cost savings resulting from carbon-related costs [26]. Turken et al. investigated the effect of environmental regulations in the form of a carbon tax on the plant capacity and location decisions of a firm. They proposed two novel policy options: (1) a per unit per mile transportation penalty and (2) a collective transportation emissions policy with a limit on total transportation emissions. Turken et al. also revealed that stricter regulations without high penalties would not ensure compliance, as the benefits from the increasing scale associated with a centralized plant frequently outweigh the regulatory penalties, and a per unit carbon tax had no effect on regional production of emissions [27]. Xu et al. investigated the joint production and pricing of a manufacturing firm with multiple products under cap-andtrade and carbon tax regulations. Their results showed that the optimal quantity of products produced under a carbon tax regulation is determined by the emissions' trading prices and the tax rate [9]. Yu and Han studied the impact of a carbon tax on carbon emissions and retail prices in a two-echelon supply chain consisting of a manufacturer and a retailer. The results indicated that with an increase in the carbon tax, both the optimal emission reduction level and the optimal retail price initially increase and then remain stable [28]. Sinha and Modak developed an economic production quantity model that elucidates a new side of $\mathrm{CO} 2$ emissions reduction [29]. Zhang investigated the impact of the carbon tax on enterprise operation and obtained the coopetition supply chain and carbon tax mechanism [30]. Chen et al. investigated how a carbon emissions taxation scheme can be designed to reduce carbon emissions [31].

In general, there are two streams in the previous literature: the optimization of the carbon tax and the relationship between the carbon tax and operation decisions in the supply chain. However, there exists a research gap in the existing literature: few papers focus on the relationship between the optimal carbon tax and supply chain coordination. Our results show that by adjusting the carbon tax, the government can promote the coordination of supply chains and reduce carbon emissions. The optimal carbon tax policy to promote coordination between the supplier and retailer is obtained by balancing the tax revenue and the product greenness.
2.2. Consumer's Reference Behavior. Consumers are always concerned about product value when choosing products on shelves. The final decision of consumption is a function of gains and losses with respect to a reference outcome [32]. Consumer's reference behavior plays an important role in this process of comparison, thereby influencing firms' operational decisions, such as product pricing and decisions regarding product greenness $[33,34]$.

Kopalle et al. studied a novel household heterogeneity translation model considering consumers' price reference behavior and developed a normative pricing policy for retailers that maximizes category profit using individual-level estimates [35]. Hsieh and Dye investigated an inventory model based on price reference effects and established an optimal dynamic pricing model to determine a pricing strategy that maximizes the discounted total profit [36]. The results suggested that the strength of the memory factor is important for a retailer to measure because a high memory factor value represents consumers with a longer memory of perceived gains or losses. The optimal discounted total profit initially increases as the memory factor increases but decreases when the memory factor is relatively high. Some dynamic price studies have also considered price reference behavior $[37,38]$. In these two previous studies, the price reference effect dominated the optimal pricing and inventory policy of the firm. The expected steady-state reference price was compared to the steady-state reference price in a model with a deterministic reference price effect, and the results showed that the former was always higher. Consumer's environmental awareness is a common behavior in real life. At present, consumers are frequently concerned about environmental protection. Green preference and green product design have attracted extensive attention from scholars. Zhang et al. investigate the impacts of consumer environmental awareness and retailer's fairness concerns on environmental quality [39]. Chen studied product design and marketing decisions based on consumer preferences for environmental attributes [40]. The development of green products depends heavily on the joint efforts of both the supply chain and the government. Therefore, the government should create a regulatory environment that is benign to green product innovation. Chitra inferred that green consumers affect marketing issues, and a preference for greenness will promote the purchase of green products [41]. The higher the consumer environmental preference is, the higher the price will be that the consumer is willing to pay for low-carbon products. Consumer's green preference is in favor of supply chain performance on the environment [42]. Moreover, as competition intensifies, the profits of manufacturers with inferior eco-friendly operations will always decrease. Li et al. infer that consumers should avoid excessive pursuit of green product design; otherwise, they hurt the environment by investigating the impact of consumer preference for green product design [43].

Consumer's reference behavior plays an important role in firms' operational decisions, and consumer environmental awareness is a common behavior in real life. The literature above is about the influence of consumers' green preference on enterprises' decision-making, such as pricing 
and green manufacturing. There exists a gap in the existing literature, which is that the consumer's behavior has not been concerned. In our research, the green preference and price reference behavior are considered.

2.3. Cooperation. Supply chain cooperation is defined as "long-term relationships where participants generally cooperate, share information, and work together to plan and even modify their business practices to improve joint performance" [44]. In general, supply chain cooperation means achieving better performance. In the supply chain, there are many coordination strategies to choose from, such as revenue sharing, buybacks, quantity discounts, and two-part tariff contracts. Among these contracts, revenue sharing has attracted the attention of many scholars and is widely used in actual supply chains [45]. For example, Xu et al. proposed a two-way revenue sharing contract to coordinate multiple distributors in a dual-channel supply chain, and the results showed that the manufacturer could prompt the retailer to cooperate by providing this contract [46]. Shi et al. studied reverse revenue-sharing contracts in a closed-loop system and proposed a function to calculate the optimal ratio of the transfer collection price. The results also suggested that reverse revenue-sharing contracts are more attractive for manufacturers than a two-part tariff [47]. Panda et al. explored channel coordination in a socially responsible manufacturer-retailer closed-loop supply chain and found that a revenue-sharing contract resolved channel conflict [48]. Modak et al. used the subgame perfect equilibrium and alternative offer bargaining strategy to resolve channel conflict and distribute surplus profit [49]. Wang and Zhao designed a revenue-sharing contract to reduce carbon emissions, and both the supplier and the retailer achieved Pareto improvement. In addition, they developed a function to determine the revenue sharing ratio using the Rubinstein bargaining model [50]. Yu et al. considered a cooperation problem in the low-carbon supply chain and found that the environmental awareness of consumers and tax rates considerably affect the emission reduction [51]. There have also been some supply chain coordination studies conducted under carbon policies. Revenue-sharing contracts have been designed to improve the performance of supply chain members based on different carbon policies [52]. Xu et al. studied the coordination problem in a two-echelon supply chain, and the effect of government policy-making on distributing the optimal emission quota was investigated. The results showed that a reasonable revenue-sharing contract is essential to increase supply chain members' profits even under low-carbon conditions [53]. Modak et al. concluded that the optimal recycling rate increases with the CSR activity of the manufacturer, and a profit-sharing contract provides the best channel performance in a closedloop distribution channel consisting of a socially responsible manufacturer, multiple retailers, and a third-party collector [54]. Feng infers that win-win results can be achieved by establishing profit-sharing contracts considering the preference of green consumers [55]. Previous papers often focus on two aspects, including the choice of contract and the conditions of the contract. However, the above literature still has a gap between cooperation and consumer's behavior. Therefore, we investigate the supply chain cooperation problem under the context of consumer's reference behavior and the carbon tax.

In summary, this study examines the interaction between supply chain cooperation and carbon taxes in a twoechelon supply chain considering consumer's behavior. Some important factors should be considered simultaneously to study this problem, such as the optimal carbon tax and consumer's behavior; however, previous research has only considered these factors separately. We also investigate the interaction between coordination and the carbon tax. The difference between our study and others in the literature is presented in Table 1.

\section{Supply Chain Model}

In this section, a two-echelon supply chain model is introduced to study green supply chain cooperation and carbon tax policy. The optimal decisions of the supply chain and the government tax are addressed. We then introduce the revenue-sharing contract used to coordinate the supply chain.

3.1. Model Assumptions. To answer the first question (is carbon tax policy favorable for improving the greenness of products?), a two-echelon supply chain model consisting of a single supplier and a single retailer without contracts is established. The manufacturer determines the product's greenness and wholesale price, and the retailer determines the retail price of the green product. The green product competes for market share with traditional products. Compared with traditional products, green products have the characteristics of low pollution and being environmentally friendly, but they may be less functional, such as electric vehicles, which has poor endurance and slow speeds. In our study, we focus on green products that are less functional than traditional products. For example, Bellos et al. noted that manufacturers offer vehicles with poor performance for customers who focus on fuel efficiency [56]. In real life, greenness reflects the environmental attributes of the product, and it is commonly used to measure how environmentally friendly a product is. In this study, we use $g$ to denote the greenness degree of green products as a measure of their environmental attributes, which is a common practice $[38,41]$.

Consumers are environmentally conscious and have environmental awareness. The utility gained from environmental attributes is assumed to be $\mathrm{kg}$, where $k$ is the sensitivity of the consumer to the greenness of a green product [38]. We use $V$ to denote the utility obtained by a consumer from a traditional product. It is commonly assumed that $V$ is uniformly distributed on $[0,1]$ to simplify the problem without affecting the conclusion [57]. Then, $\alpha V$ is the utility from the green product, where $\alpha \in(0,1)$ is the functional attribute coefficient of the green product that reflects its weak functional performance compared with the traditional product. 
TABle 1: Differences between our study and the available literature.

\begin{tabular}{lccc}
\hline Literature & Decisions under the carbon tax & Optimal carbon tax & Consumer's behavior \\
\hline Yu and Han [28] & $\sqrt{ }$ & $\sqrt{ }$ & Coordination \\
Ulph and Ulph [22] & & $\sqrt{ }$ & $\sqrt{ }$ \\
Hsieh and Dye [34] & $\sqrt{ }$ & & $\sqrt{ }$ \\
Cao et al. [47] & $\sqrt{ }$ & $\sqrt{ }$ \\
Xu et al. [48] & $\sqrt{ }$ & $\sqrt{ }$ \\
Our paper & & & $\sqrt{ }$ \\
\hline
\end{tabular}

In real life, consumers usually compare prices between two similar products. Let $\beta$ be the consumers' recognition level of the reference price [35]. Therefore, the utility of green products is obtained from four parts: a positive part from the basic utility $(\alpha V)$, a negative part from the price $(p)$, a positive part from the environmental consciousness $(\mathrm{kg})$, and a negative part from the price reference $\left(\beta\left(p-p_{n}\right)\right)$. The utility to a consumer of green products and traditional products can thus be expressed as follows:

$$
\left\{\begin{array}{l}
u_{n}=V-p_{n}, \\
u_{g}=\alpha V-p+k g-\beta\left(p-p_{n}\right) .
\end{array}\right.
$$

Table 2 summarizes the notation used in this study.

3.2. Model and Solution. Consumers choose between green and traditional products by comparing utility: when $u_{g}>u_{n}$ and $u_{g}>0$, consumers will purchase the green product, whereas when $u_{n}>u_{g}$ and $u_{n}>0$, consumers will purchase the traditional product. As a result, demand is obtained as shown in equation (2). The proof of the demand function is given in Appendix A.

$$
\left\{\begin{array}{l}
q=\frac{(\alpha+\beta) p_{n}-(1+\beta) p+k g}{\alpha(1-\alpha)} \\
q_{n}=1-\frac{(1+\beta)\left(p_{n}-p\right)+k g}{1-\alpha} .
\end{array}\right.
$$

The manufacturer determines the wholesale price and greenness of the green product. Let $\gamma$ denote the cost rate of technology development; then, the total development cost is $(1 / 2) \gamma g^{2}$, which is convexly increasing with the greenness [40]. In addition, $(e-g)$ is a linear function of the unit carbon emissions for green products [58]. Therefore, the profit function for the manufacturer is obtained from three parts: a positive part from the wholesale $((w-c) q)$, a negative part from green technology development $\left(\left(\gamma g^{2} / 2\right)\right)$, and a negative part from the carbon tax $(t(e-g) q)$. The manufacturer's decision model is as follows:

$$
\underset{w, g}{\operatorname{Max}} \pi_{M}=(w-c-t(e-g)) q-\frac{\gamma g^{2}}{2} .
$$

The retailer's decision problem is then formulated as follows:

$$
\underset{p}{\operatorname{Max}} \pi_{R}=(p-w) q
$$

The optimal solutions for the retailer and manufacturer are derived as the following theorem by substituting the demand function into the equation above. The proof is presented in Appendix A.

Theorem 1. The optimal solutions for both parties are

$$
\left\{\begin{array}{l}
w=\frac{2 \gamma p_{n} \alpha^{3}+2 A_{1} \gamma \alpha^{2}+B_{1} \alpha+t^{2}(1+\beta)\left(\beta p_{n}+k e\right)}{(1+\beta)\left(t^{2}(1+\beta)-4 \gamma \alpha(1-\alpha)\right)} \\
g=\frac{\left((1+\beta)(t e+c)-(\alpha+\beta) p_{n}-k e\right) t}{t^{2}(1+\beta)-4 \gamma \alpha(1-\alpha)} \\
p=\frac{3 \gamma p_{n} \alpha^{3}+2 A_{2} \gamma \alpha^{2}+B_{2} \alpha+t^{2}(1+\beta)\left(\beta p_{n}+k e\right)}{(1+\beta)\left(t^{2}(1+\beta)-4 \gamma \alpha(1-\alpha)\right)}
\end{array}\right.
$$

The corresponding profits are

$$
\left\{\begin{array}{l}
\pi_{m}=-\frac{\left(\left(t e+c-p_{n}\right) \beta+(-k+t) e-\alpha p_{n}+c\right)^{2} \gamma}{2\left(t^{2} \beta+t^{2}+4(-1+\alpha) \gamma \alpha\right)(\beta+1)} \\
\pi_{r}=-\frac{\left(\left(t e+c-p_{n}\right) \beta+(-k+t) e-\alpha p_{n}+c\right)^{2}(-1+\alpha) \alpha \gamma^{2}}{\left(4 \alpha^{2} \gamma-4 \alpha \gamma+(\beta+1) t^{2}\right)^{2}(\beta+1)} .
\end{array}\right.
$$

According to this theorem, price and greenness decisions are directly affected by the carbon tax rate. Facing a higher carbon tax and development cost, the manufacturer and retailer will reduce the greenness of products and the sale price with increasing carbon tax. However, when facing a lower carbon tax, the greenness and price will increase with increasing carbon tax (the details are shown in Appendix B, equations (1) and (5)). Next, we investigate the effects of these parameters on the product greenness. The proofs are provided in Appendix B.

Proposition 1. The effects of the carbon tax rate, price recognition level, development cost, and functional attribute coefficient on product greenness are as follows:

(1) There exist some thresholds, $\widehat{t}_{1}$ and $\widehat{\gamma}_{1}$, for which $g$ decreases with increasing $t$ when $\gamma>\widehat{\gamma}_{1}$ and $t>\widehat{t}_{1}$; else $g$ increases with increasing $t$. 
TABle 2: Notations.

\begin{tabular}{lc}
\hline Parameters & Definition \\
\hline$p, p_{n}$ & Prices of the green product and traditional product, respectively \\
$w$ & Demand for the green product and traditional product, respectively \\
$g$ & Wholesale price \\
$t$ & Product greenness \\
$\gamma$ & Carbon tax rate \\
$c$ & Cost rate of technology development \\
$e$ & Unit product cost of the green product \\
$\alpha$ & Initial unit carbon emissions \\
$\beta$ & Functional attribute coefficient of the green product function \\
$k$ & Consumers' recognition level of the reference price \\
$V$ & Sensitivity of consumers to product greenness \\
$\eta$ & Utility obtained by a consumer from the traditional product \\
$\lambda$ & Proportion of the total revenue obtained by the retailer \\
\hline
\end{tabular}

(2) There exist some thresholds, $\widehat{t}_{2}$ and $\widehat{\gamma}_{2}$, for which $g$ decreases with increasing $\beta$ when $\gamma>\widehat{\gamma}_{2}$ and $t>\widehat{t}_{2}$; else $g$ increases with increasing $\beta$.

(3) $g$ increases with increasing $k$, decreases with increasing $\gamma$, and initially increases and then decreases with increasing $\alpha$.

We can conclude that the carbon tax, development cost, price recognition level, greenness sensitivity, and functional attribute coefficient all influence the greenness in Proposition 1 . When the carbon tax is low, the manufacturer incurs less cost to improve the greenness of the products. As a result, the greenness increases with the carbon tax. In addition, if the carbon tax is high and the development cost is low, the greenness of the products will increase with increasing carbon tax because the tax is the crucial factor in decisions. In contrast, if the carbon tax is high and development costs are also high, the greenness of products will decrease because the manufacturer will choose to reduce development costs. Therefore, pollution will not be reduced as the carbon tax increases in some cases. Facing high development costs, the manufacturer will not improve greenness unless it is promoted by a lower carbon tax. A numerical simulation of this scenario is shown in Figure 1.

Similarly, the results show that greenness is affected by the consumers' price reference behavior. When the carbon tax is low, the negative effect of price increases when consumers have higher concerns about price. Therefore, the manufacturer will offset this negative effect by improving the greenness of products. When the carbon tax is high and the development cost is low, the greenness of products will increase under a high consumer concern about price. In contrast, if the carbon tax is high and the development cost is high, the greenness will decrease because the manufacturer will choose to reduce development costs. Numerical simulations of these scenarios are shown in Figure 2.

In addition, greenness sensitivity and the functional attribute coefficient also affect greenness. The greenness increases with increasing greenness sensitivity of consumers. High greenness sensitivity can promote more green products. This means that the government can promote green production by

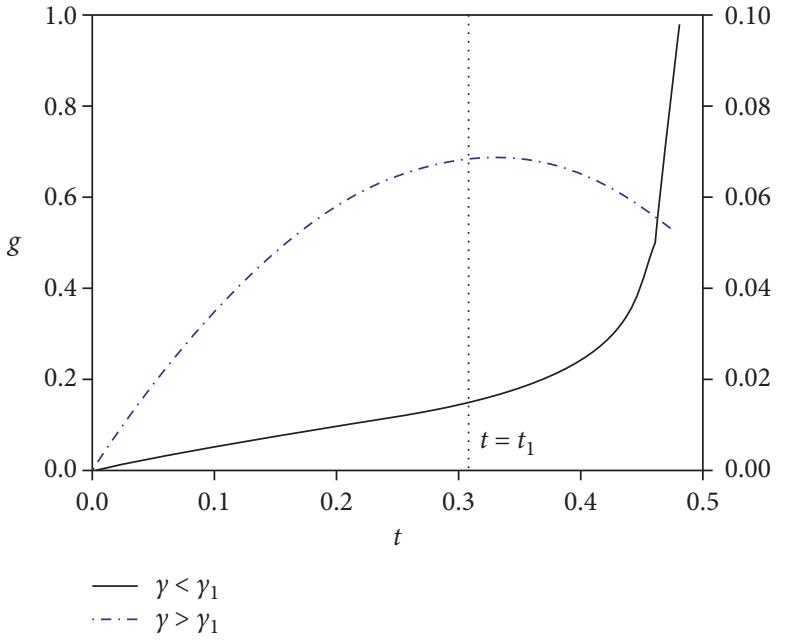

Figure 1: Effects of carbon taxes on greenness.

increasing the green consciousness of consumers. Moreover, the greenness decreases with increasing development cost. A higher degree of greenness is obtained when manufacturers face lower development costs. In addition, greenness first increases and then decreases with the increase in the functional attribute coefficient. When the functional attribute of the green product is low, the manufacturer will produce a lower greenness product with increases in the functional attribute coefficient. In contrast, the manufacturer will produce a product with higher greenness with an increase in the functional attribute after a functional threshold has been reached. Numerical simulations of these scenarios are shown in Figure 3.

Overall, consumers' reference behavior plays a positive role in promoting green production. However, the carbon tax is not effective for improving green products in some cases. For example, if the carbon tax is high and the development cost is also high, the greenness of products will decrease. Therefore, we next investigate the optimal carbon tax.

First, an optimal carbon tax is defined as that which provides the maximum greenness without losing total tax revenue. The result is provided in Proposition 2, and the proofs can be found in Appendix C. 


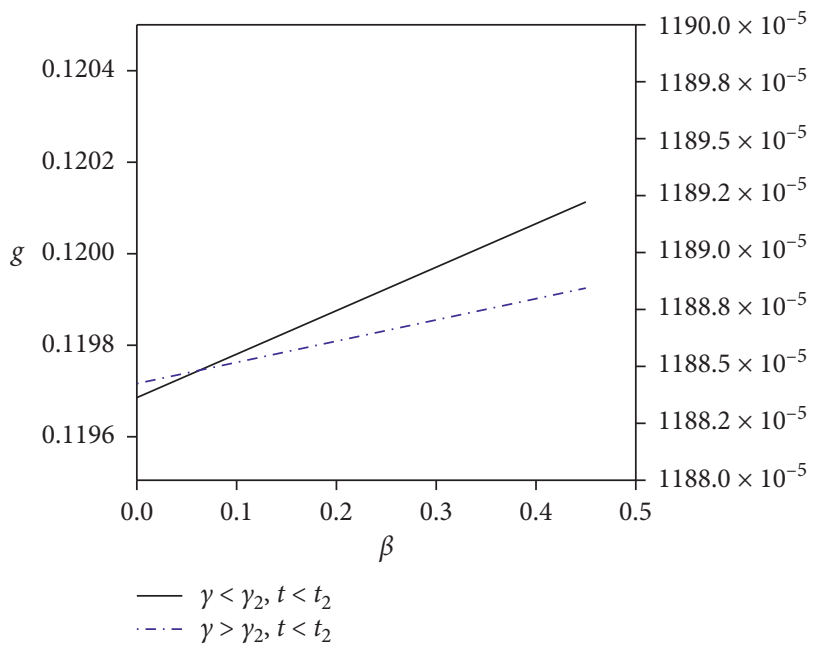

(a)

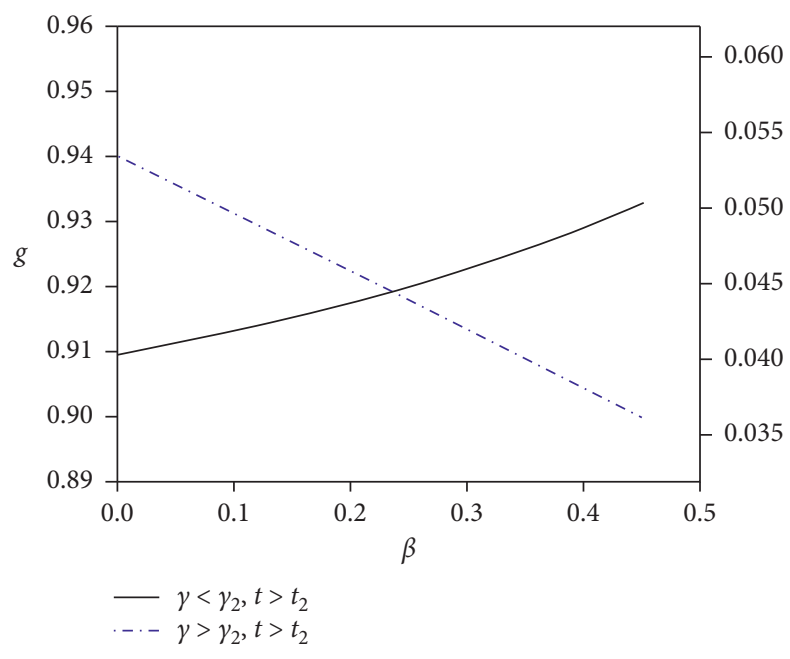

(b)

FiguRE 2: Effects of consumers' price reference behavior on greenness. (a) Low-carbon tax rate. (b) High carbon tax rate.

Proposition 2. The optimal carbon tax is defined as follows:

$$
t^{*}= \begin{cases}\frac{M-\sqrt{M^{2}-N}}{e(1+\beta)}, & 0<\gamma<\widehat{\gamma}_{3} \\ \frac{P-\sqrt{P^{2}-Q}}{2(1+\beta) M}, & \widehat{\gamma}_{3}<\gamma<\widehat{\gamma}_{1}, \\ \widehat{t}_{1}, & \widehat{\gamma}_{1}<\gamma .\end{cases}
$$

The optimal carbon tax is obtained in Proposition 2 based on the manufacturer's development cost to maximize greenness without losing the total carbon tax revenue. We can observe that the crucial factor is the development cost. An appropriate carbon tax policy should be chosen when facing different production technologies to ensure greenness and total tax revenue. In addition, it is easily observed that the maximum greenness is obtained when the development cost is high, whereas the maximum tax is obtained when the development cost is lower, but some of the greenness is lost. A numerical simulation of this scenario is shown in Figure 4.

3.3. Supply Chain Coordination. It is also important for supply chains to establish green supply chain models by integrating internal and external resources to make decisions, which enables supply chains to achieve better performance by improving cooperation $[59,60]$. However, most studies on coordination have mainly focused reducing emissions and improving profit. Few studies have investigated the relationship between carbon taxes and supply chain cooperation.

In this section, we study the impact of carbon taxes and consumer's behavior on supply chain coordination, where the manufacturer is the leader, and the retailer is the follower. A revenue-sharing contract is introduced to achieve coordination. Let $\eta$ denote the proportion of total revenue obtained by the retailer; then, the manufacturer's decision model is as follows:

$$
\operatorname{Max}_{w, g} \pi_{M}^{C}=((1-\eta) p+w-c-t(e-g)) q-\frac{\gamma g^{2}}{2} .
$$

The retailer's decision problem can be described as follows:

$$
\underset{p}{\operatorname{Max}} \pi_{R}^{C}=(\eta p-w) q .
$$

The optimal solutions for the retailer and manufacturer are derived with the following theorem by substituting the demand function into the equation above. The proof is found in Appendix D.

Theorem 2. The greenness is defined as follows:

$$
g=\frac{t\left(-\alpha p_{n}+e t(\beta+1)+\left(c-p_{n}\right) \beta-k e+c\right)}{2 \gamma(1+\eta) \alpha^{2}-2 \gamma(1+\eta) \alpha+t^{2}(\beta+1)} .
$$

Then, the profits of both parties are the following:

$$
\left\{\begin{array}{l}
\pi_{m}=-\frac{\left(\left(t e+c-p_{n}\right) \beta+(-k+t) e-\alpha p_{n}+c\right)^{2} \gamma}{2\left(t^{2} \beta+t^{2}+4(-1+\alpha) \gamma \alpha\right)(\beta+1)}, \\
\pi_{r}=-\frac{\left(\left(t e+c-p_{n}\right) \beta+(-k+t) e-\alpha p_{n}+c\right)^{2}(-1+\alpha) \alpha \gamma^{2}}{\left(4 \alpha^{2} \gamma-4 \alpha \gamma+(\beta+1) t^{2}\right)^{2}(\beta+1)} .
\end{array}\right.
$$

We investigate the impact of the carbon tax on promoting the coordination of the supply chain by comparing the profit changes of the two partners after the introduction of the revenue-sharing contract in Proposition 3. The proofs are provided in Appendix E.

Proposition 3. Coordination can be promoted by increasing the carbon tax. 


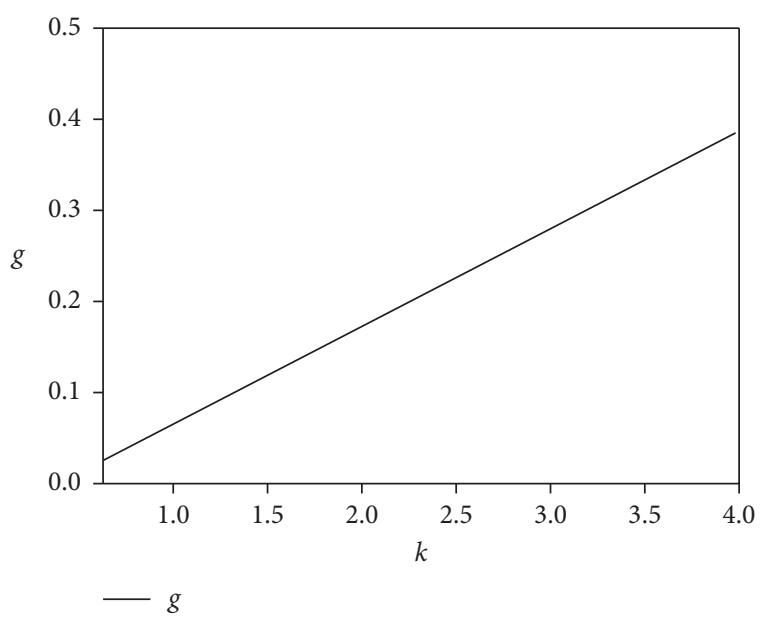

(a)

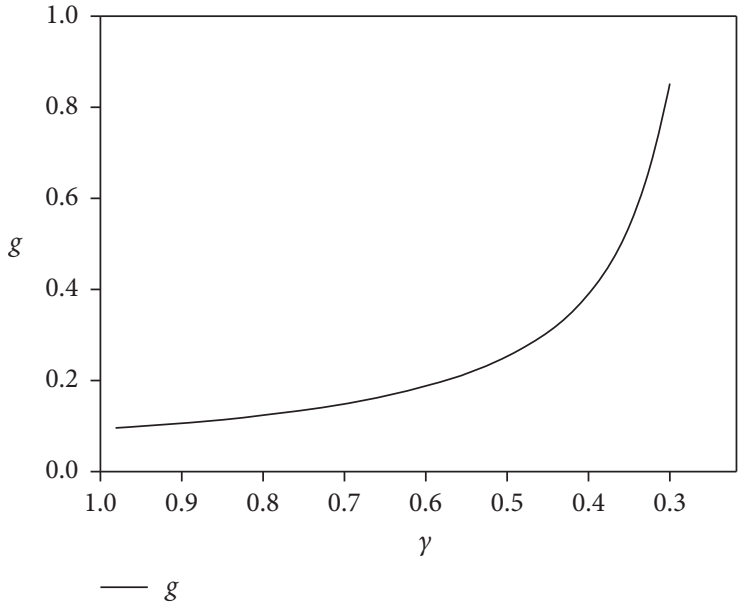

(b)

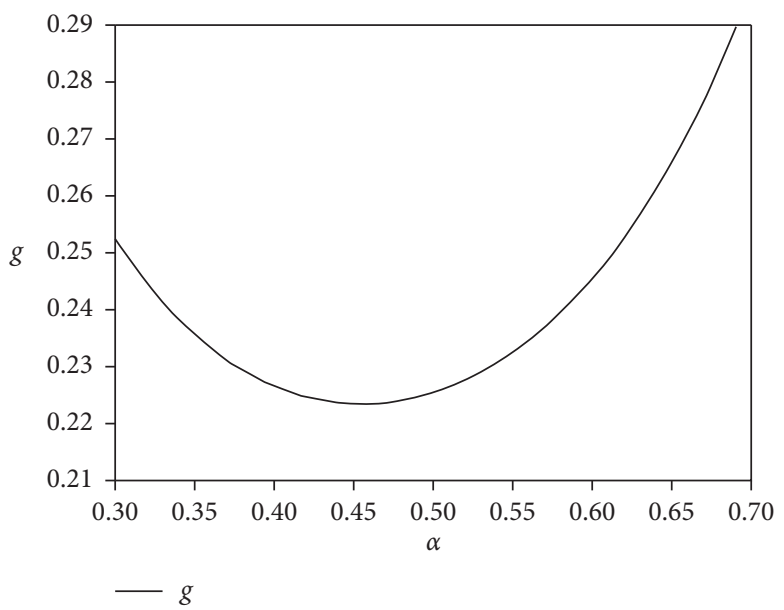

(c)

Figure 3: Effects of parameters on greenness. (a) Greenness sensitivity. (b) Development cost. (c) Functional attribute coefficient.

When the profits of both the retailer and the manufacturer improve simultaneously, coordination is achieved. By comparing equations (11) and (6), we find that the revenue-sharing contract improves the retailer's profit only when $\eta \in\left(\eta_{1}, 1\right)$, whereas the manufacturer always benefits from the contract. The range of $\eta$ depends on the carbon tax rate. When $\eta$ is in the given range, the retailer and manufacturer achieve Pareto improvement. Furthermore, the range expands as the carbon tax rate increases. Therefore, the government can promote supply chain collaboration by increasing the carbon tax. Based on the previous results for the optimal carbon tax, we next investigate how to achieve coordination when the supply chain faces the optimal carbon tax. Figure 5 shows the Pareto improvement region.

According to the assumptions described above, the manufacturer acts as the leader, and the retailer acts as a follower. It is reasonable that the proportion of profit received by the retailer is decided by the manufacturer. Therefore, it is necessary to investigate whether the proportion decided by the leader is in the region in which coordination is achieved. A parameter $\lambda$ is introduced to denote the strength of a partner in the supply chain. Let $\lambda_{m} \in(0.5,1)$ and $\lambda_{r}=1-\lambda_{m}$ represent the power of the manufacturer and the retailer, respectively. Then, we consider a simple function, $\left(\lambda_{r} / \lambda_{m}\right)$, to determine $\eta$, which is the proportion of revenue received by the retailer. The retailer retains the maximum revenue when the power of the two parties is equal (i.e., $\lambda_{m}=\lambda_{r}=0.5$ ), whereas all of the benefits go to the leader when the power of the manufacturer is overwhelming compared with that of the retailer (i.e., $\lambda_{m}=1$ ). Similar to Proposition 2, the optimal carbon tax is obtained under the revenue-sharing contract as follows:

$$
t^{*}= \begin{cases}\frac{M-\sqrt{M^{2}-(1+\eta / 2) N}}{e(1+\beta)}, & 0<\gamma<\widehat{\gamma}_{2}^{C}, \\ \frac{(1+\eta / 2) P-\sqrt{(1+\eta / 2)^{2} P^{2}-(1+\eta / 2) Q}}{2(1+\beta) M}, & \hat{\gamma}_{2}^{C}<\gamma<\widehat{\gamma}_{1}, \\ \widehat{t}_{1}, & \widehat{\gamma}_{1}<\gamma .\end{cases}
$$




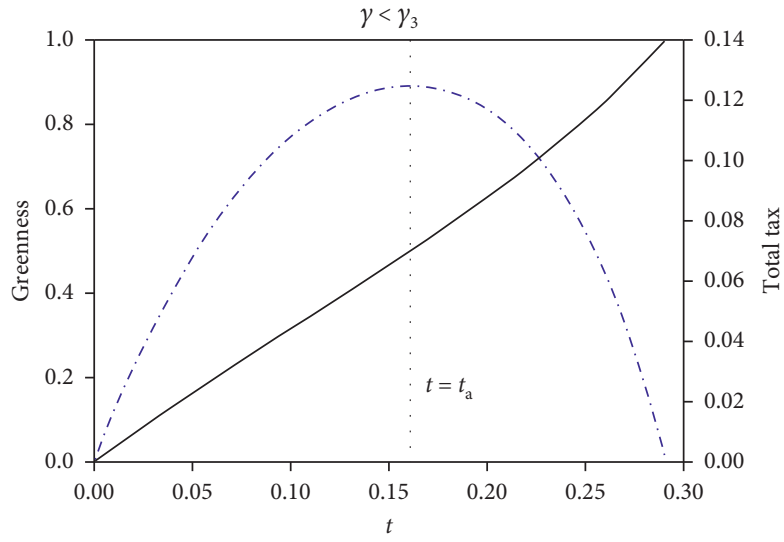

$\begin{array}{ll}- & \text { Greenness } \\ -.- & \text { Total tax }\end{array}$

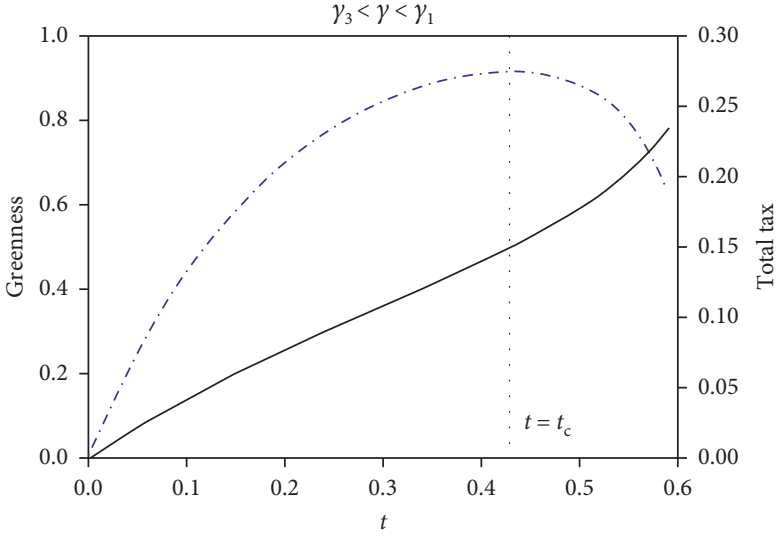

- Greenness

(a)

(b)

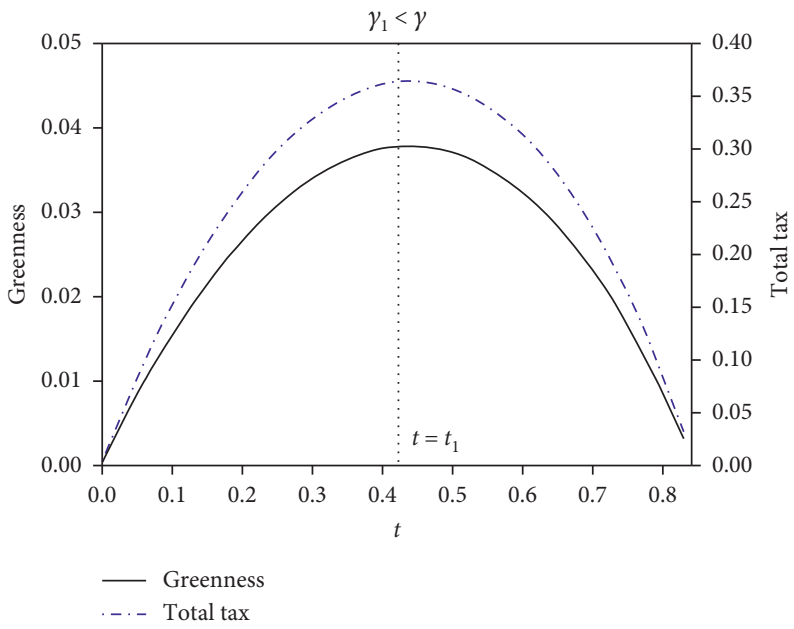

(c)

Figure 4: Determination of the optimal carbon tax. (a) $0<\gamma<\widehat{\gamma}_{3}$. (b) $\hat{\gamma}_{3}<\gamma<\widehat{\gamma}_{1}$. (c) $\hat{\gamma}_{1}<\gamma$.

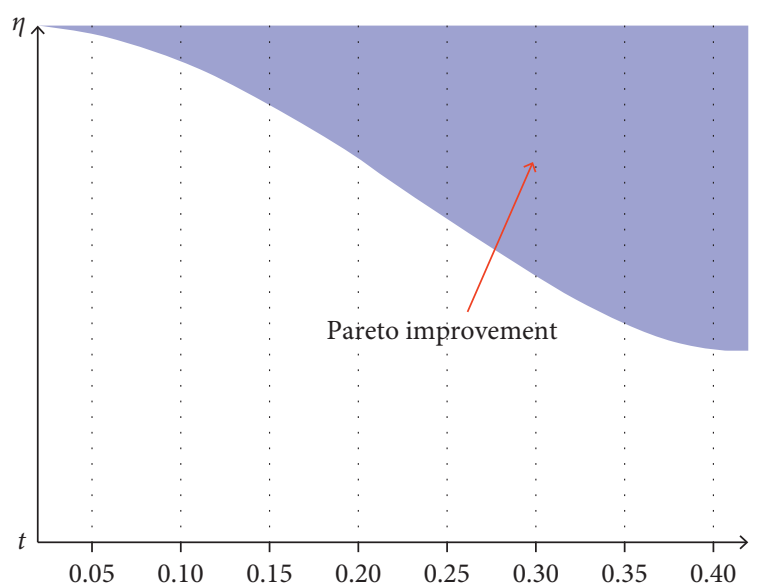

Figure 5: Pareto improvement region with increasing carbon tax.

Proposition 4 is designed to answer the question of whether cooperation will be achieved; the proofs are found in Appendix F.
Proposition 4. Coordination will be achieved if the power of the manufacturer is low (i.e., $0.5<\lambda_{m}<\widehat{\lambda}_{1}$ ). Moreover, when the power of the manufacturer is at a medium level (i.e., $\hat{\lambda}_{1}<\lambda_{m}<\hat{\lambda}_{2}$ ), coordination can be achieved, but part of the total tax revenue will be lost, if the development cost is low (i.e., $\gamma<\widehat{\gamma}_{1}$ ). In other cases (i.e., $\gamma>\hat{\gamma}_{1}$ or $\hat{\lambda}<\lambda_{m}$ ), coordination cannot be achieved because the power of the manufacturer is overwhelming.

Coordination situations for different manufacturer power levels are present in Table 3. The achievement of coordination is decided by the power of the manufacturer and the optimal carbon tax faced by the supply chain. Based on Proposition 3, coordination can be promoted if the government adjusts the carbon tax. On the other hand, coordination can easily be achieved under the optimal carbon tax if the power of the manufacturer is low. In addition, there are two possibilities when the power of the manufacturer is at a medium level. If the development cost is too high, adjusting the tax will lead to an unknown result: the greenness and total tax revenue may both decline at the same 
TABLE 3: Coordination situations for different manufacturer power levels.

\begin{tabular}{|c|c|c|c|}
\hline Power of the manufacturer & Coordination & Greenness & Total carbon tax revenue \\
\hline $\begin{array}{l}0.5<\lambda_{m}<\widehat{\lambda}_{1} \\
\widehat{\lambda}_{1}<\lambda_{m}<\widehat{\lambda}_{2}, \gamma<\widehat{\gamma}_{1} \\
\widehat{\lambda}_{1}<\lambda_{m}<\widehat{\lambda}_{2}, \gamma<\widehat{\gamma}_{1} \\
\gamma>\widehat{\gamma}_{1}\end{array}$ & $\begin{array}{c}\text { Achieve } \\
\text { Achieve } \\
\text { Cannot achieve } \\
\text { Cannot achieve }\end{array}$ & $\begin{array}{l}\text { Improve } \\
\text { Improve }\end{array}$ & $\begin{array}{l}\text { Improve } \\
\text { Decline }\end{array}$ \\
\hline
\end{tabular}

time. If the development cost is lower, the greenness may be improved with a loss of revenue by increasing the carbon tax. However, when the power of the manufacturer is strong, the region $\delta=\left(\eta_{1}, 1\right)$ cannot be achieved.

According to our theory, the government can promote the coordination between the manufacturer and the retailer by adjusting the carbon tax. When the power of the manufacturer increases, the government still achieves coordination by raising the carbon tax. In general, cooperation is achieved, and the government plays a key role in promoting cooperation.

The effects of consumers' behavior on supply chain coordination are also investigated in the next proposition. The proofs are provided in Appendix G.

Proposition 5. Price reference behavior can promote supply chain coordination, but green preference cannot.

From the previous results, price reference has a complex impact on the supply chain. First, the increasing sensitivity of customers to price will promote supply chain coordination because this negative impact can be mitigated by cooperation. In addition, price reference behavior also affects the green decisions of the supply chain in a complex manner. In contrast, the mechanism by which consumer' green preferences influence the supply chain is relatively simple. Greenness increases with increasing greenness preference, and green preference has no effect on the coordination of the supply chain.

\section{Conclusion}

This study examines the interaction between supply chain cooperation and the carbon tax problem in a two-echelon supply chain under consumer's reference behavior. The optimal carbon tax policy is obtained based on analysis of the carbon tax, green investment coefficient, and degree of consumer's price reference. The optimal carbon tax is defined as the simultaneous optimization of total tax revenue and product greenness. In addition, coordination is achieved by introducing revenue-sharing contracts. The impact of consumers' reference behavior and the carbon tax on supply chain coordination is also investigated. The results are as follows:

(1) The greenness increases with increasing carbon tax when the carbon tax is low. In addition, if the carbon tax is higher and the development cost is low, the greenness of products will increase with increasing carbon tax. Conversely, if the carbon tax is higher and the development cost is also high, the greenness of products will decrease.
(2) When the carbon tax is low, the negative effect of price increases as consumer concerns about price increase. Therefore, the manufacturer offsets the negative effect by improving the greenness. When the carbon tax is higher and development cost is low, the greenness of products will increase with high consumer's concern about price. In contrast, if the carbon tax is higher and the development cost is high, the greenness will decrease.

(3) The greenness increases with an increasing greenness preference of consumers. Their preference behavior can promote more green products. This means that the government can promote green production by promoting the green consciousness of consumers. Moreover, the greenness decreases with increasing development cost. A higher greenness is obtained when manufacturers face lower development costs. In addition, greenness first increases and then decreases with increases in the functional attribute coefficient. When the functional attribute of the green product is low, the manufacturer will produce a lower greenness product with an increase in the functional attribute. In contrast, the manufacturer will produce a higher greenness product with an increase in the functional attribute after a functionality threshold.

(4) We investigated the impact of the carbon tax on promoting the coordination of the supply chain by comparing the profit changes of two partners after the introduction of a revenue-sharing contract in Proposition 3. We found that coordination could be promoted by increasing the carbon tax.

(5) The achievement of coordination depends on the type of manufacturer. If the power of the manufacturer is low, coordination can be achieved under the optimal carbon tax. If the power of the manufacturer is at a medium level, coordination can be achieved by increasing the carbon tax, and improved greenness will be realized with a loss of revenue. However, when the power of the manufacturer is strong, coordination cannot be achieved.

In this study, we focused on the interaction between a carbon tax and supply chain cooperation. However, other carbon policies (e.g., a cap-and-trade policy) and supply chain structures are worth exploring. For example, it would be interesting to investigate the effects on a supply chain structure consisting of the retailer as the leader under a complex carbon policy. 


\section{Appendix}

\section{A. Proof of Theorem 1}

The demand function can be written as

$$
\left\{\begin{array}{l}
q=P\left\{u_{g} \geq u_{n}, u_{g} \geq 0\right\} \\
q_{n}=P\left\{u_{n}>u_{g}, u_{n} \geq 0\right\}
\end{array}\right.
$$

After replacing $u_{n}$ and $u_{g}$, we have

$$
\left\{\begin{array}{l}
q=P\left\{\alpha v-p+k g-\beta\left(p-p_{n}\right)-\left(v-p_{n}\right) \geq 0, \alpha v-p+k g-\beta\left(p-p_{n}\right) \geq 0\right\} \\
q_{n}=P\left\{v-p_{n}-\left(\alpha v-p+k g-\beta\left(p-p_{n}\right)\right)>0, v-p_{n} \geq 0\right\}
\end{array}\right.
$$

Given that $V$ is uniformly distributed on $[0,1]$, the demand function is

$$
\left\{\begin{array}{l}
q=\frac{(\alpha+\beta) p_{n}-(1+\beta) p+k g}{\alpha(1-\alpha)} \\
q_{n}=1-\frac{(1+\beta)\left(p_{n}-p\right)+k g}{1-\alpha}
\end{array}\right.
$$

The condition $k>\left((1+\beta) p-(\alpha+\beta) p_{n} / g\right)$ is necessary to ensure nonnegativity. The retailer problem is addressed first, and we have

$$
p=\frac{(\alpha+\beta) p_{n}+(1+\beta) w+k g}{2(1+\beta)} .
$$

Then, substitute $p$ into the manufacturer's profit function. Solving the optimal $w$ and $g$ simultaneously yields

$$
\begin{aligned}
& w=\frac{(\alpha+\beta) p_{n}+(1+\beta)(c+t(e-g))+k g}{2(1+\beta)}, \\
& g=\frac{t\left((\alpha+\beta) p_{n}-(1+\beta) w+k e\right)}{2 \gamma \alpha(1-\alpha)}
\end{aligned}
$$

Then we have

$$
\begin{aligned}
& \int w=\frac{2 \gamma p_{n} \alpha^{3}+2 A_{1} \gamma \alpha^{2}+B_{1} \alpha+t^{2}(1+\beta)\left(\beta p_{n}+k e\right)}{(1+\beta)\left(t^{2}(1+\beta)-4 \gamma \alpha(1-\alpha)\right)}, \\
& \left\{g=\frac{\left((1+\beta)(t e+c)-(\alpha+\beta) p_{n}-k e\right) t}{t^{2}(1+\beta)-4 \gamma \alpha(1-\alpha)}\right. \\
& p=\frac{3 \gamma p_{n} \alpha^{3}+2 A_{2} \gamma \alpha^{2}+B_{2} \alpha+t^{2}(1+\beta)\left(\beta p_{n}+k e\right)}{(1+\beta)\left(t^{2}(1+\beta)-4 \gamma \alpha(1-\alpha)\right)} \\
& \left\{\begin{array}{l}
A_{1}=(1+\beta)(c+t e)+k e-(1-\beta) p_{n} \\
A_{2}=(1+\beta)(c+t e)+3 k e-(3-\beta) p_{n}
\end{array}\right. \\
& \left\{\begin{array}{l}
B_{1}=-2 \gamma\left((1+\beta)(c+t e)+k e+\beta p_{n}\right)+t^{2}(1+\beta) p_{n} \\
B_{2}=-\gamma\left((1+\beta)(c+t e)+3 k e+3 \beta p_{n}\right)+t^{2}(1+\beta) p_{n} .
\end{array}\right.
\end{aligned}
$$

Notes that we have $(\alpha+\beta) p_{n}+k e-(1+\beta)(t e+c)>0$. The concavity condition is $4 \alpha \gamma(1-\alpha)-(1+\beta) t^{2}>0$.

\section{B. Proof of Proposition 1}

(1) The first derivative of $g$ in $t$ is

$$
\begin{aligned}
& \frac{\partial g}{\partial t}=\frac{-4 \gamma \alpha^{3} p_{n}+4 \gamma A_{3} \alpha^{2}+B_{3} \alpha-t^{2}(1+\beta)\left((1+\beta) c-k e-\beta p_{n}\right)}{\left(t^{2}(1-\beta)-4 \gamma \alpha(1-\alpha)\right)^{2}}, \\
& \left\{\begin{array}{l}
A_{3}=(1+\beta)(c+2 t e)-k e+(1-\beta) p_{n}, \\
B_{3}=-4 \gamma\left((1+\beta)(c+2 t e)-k e-\beta p_{n}\right)+t^{2}(1+\beta) p_{n} .
\end{array}\right.
\end{aligned}
$$

We have a threshold

$$
\begin{aligned}
& \widehat{\gamma}_{1}=-\frac{t^{2}(1+\beta)\left((\alpha+\beta) p_{n}+k e-(1+\beta) c\right)}{4 \alpha(1-\alpha)\left((\alpha+\beta) p_{n}+k e-(1+\beta)(c+2 t e)\right)}, \\
& \widehat{t}_{1}=\frac{(\alpha+\beta) p_{n}+k e-(1+\beta) c}{2(1+\beta) e} .
\end{aligned}
$$

When $\gamma>\widehat{\gamma}_{1}$ and $t>\widehat{t}_{1}, g$ is decreasing in $t$. By contrast, $g$ is increasing in $t$ in other cases.

(2) The first derivative of $g$ in $\beta$ is

$$
\frac{\partial g}{\partial \beta}=\frac{-4 \alpha(1-\alpha)\left(t e+c-p_{n}\right) \gamma+t^{2}\left(k e+\alpha p_{n}-p_{n}\right)}{\left(t^{2}(1+\beta)-4 \alpha(1-\alpha) \gamma\right)^{2}}
$$

We have a threshold

$$
\begin{aligned}
& \widehat{\gamma}_{2}=-\frac{t^{2}\left(k e-(1-\alpha) p_{n}\right)}{4 \alpha(1-\alpha)\left(t e+c-p_{n}\right)}, \\
& \widehat{t}_{2}=\frac{p_{n}-c}{e} .
\end{aligned}
$$

Review we have $(\alpha+\beta) p_{n}+k e-(1+\beta)(t e+c)>0$; therefore we can find that

$$
t<\frac{p_{n}-c}{e}+\frac{k e-(1-\alpha) p_{n}}{(1+\beta) e} .
$$

(i) When $k e-(1-\alpha) p_{n}<0$, then $t<\widehat{t}_{2}$ is inevitable. Therefore $(\partial g / \partial \beta)>0$ is correct.

(ii) When $k e-(1-\alpha) p_{n}>0$, we can find that $(\partial g / \partial \beta)<0$ if $\gamma>\widehat{\gamma}_{2}$ and $t>\widehat{t}_{2} ;(\partial g / \partial \beta)<0$ in other cases.

(3) The first derivative of $g$ in $k$ and $\gamma$ is 


$$
\left\{\begin{array}{l}
\frac{\partial g}{\partial \gamma}=-\frac{4 \alpha(1-\alpha)\left((\alpha+\beta) p_{n}+k e-(1+\beta)(t e+c)\right)}{\left(4 \gamma \alpha(1-\alpha)-t^{2}(1+\beta)\right)^{2}}<0, \\
\frac{\partial g}{\partial k}=\frac{t e}{4 \gamma \alpha(1-\alpha)-t^{2}(1+\beta)}>0 .
\end{array}\right.
$$

(4) The first derivative of $g$ in $\alpha$ is

$$
\frac{\partial g}{\partial \alpha}=\frac{-X t}{\left(4 \alpha(1-\alpha) \gamma-t^{2}(1+\beta)\right)^{2}} .
$$

And $X=-4 \alpha^{2} \gamma p_{n}+\left(4(1+\beta)(t e+c)-4 k e-4 p_{n}\right)$ $(2 \alpha+1) \gamma+p_{n} t^{2}(1+\beta)$ is a quadratic function. The range of $\alpha$ in $4 \alpha \gamma(1-\alpha)-(1+\beta) t^{2}>0$ is

$$
\left\{\begin{array}{l}
\alpha_{1}=\frac{\gamma+\sqrt{\gamma^{2}-\gamma t^{2}(1+\beta)}}{2 \gamma}, \\
\alpha_{2}=\frac{\gamma-\sqrt{\gamma^{2}-\gamma t^{2}(1+\beta)}}{2 \gamma} .
\end{array}\right.
$$

By substituting those into $X$, we have

$$
\left\{\begin{array}{l}
\left.X\right|_{\alpha=\alpha_{1}}=4 \sqrt{\gamma^{2}-\gamma t^{2}(1+\beta)} T-2\left(\gamma-t^{2}(1+\beta)\right) p_{n}, \\
\left.X\right|_{\alpha=\alpha_{2}}=-4 \sqrt{\gamma^{2}-\gamma t^{2}(1+\beta)} T-2\left(\gamma-t^{2}(1+\beta)\right) p_{n}<0 .
\end{array}\right.
$$

And $T=(1+\beta)(t e+c)-k e-((1 / 2)+\beta) p_{n}<0$. We can find

$$
\begin{aligned}
\left.X\right|_{\alpha=\alpha_{1}} \times\left. X\right|_{\alpha=\alpha_{2}}= & -4\left(\gamma-t^{2}(1+\beta)\right) \\
& \cdot\left(4\left(\beta p_{n}+k e-(1+\beta)(t e+c)\right)^{2}\right. \\
& \left.+p_{n}^{2} t^{2}(1+\beta)\right)<0 .
\end{aligned}
$$

Therefore, $\left.X\right|_{\alpha=\alpha_{1}}>0$. There only exist a $\widehat{\alpha} \in\left(\alpha_{2}, \alpha_{1}\right)$ that makes $(\partial g / \partial \alpha)=0$. And $(\partial g / \partial \alpha)>0$ if $\alpha \in\left(\alpha_{2}, \widehat{\alpha}\right) ;(\partial g / \partial \alpha)<0$ if $\alpha \in\left(\widehat{\alpha}, \alpha_{1}\right)$.

(5) The first derivative of $p$ in $t$ is

$$
\begin{aligned}
& \frac{\partial p}{\partial t}=-\frac{2 \alpha(\alpha-1)\left(\left(e(1+\beta) t^{2} / 2\right)+\left(-p_{n} \alpha-k e+\left(c-p_{n}\right) \beta+c\right) t-2 e \alpha \gamma(\alpha-1)\right) \gamma}{\left((1+\beta) t^{2}+4 \alpha \gamma(\alpha-1)\right)^{2}}, \\
& \left\{\begin{array}{l}
A_{3}=(1+\beta)(c+2 t e)-k e+(1-\beta) p_{n}, \\
B_{3}=-4 \gamma\left((1+\beta)(c+2 t e)-k e-\beta p_{n}\right)+t^{2}(1+\beta) p_{n} .
\end{array}\right.
\end{aligned}
$$

The discriminant of quadratic function

$\frac{e(1+\beta) t^{2}}{2}+\left(-p_{n} \alpha-k e+\left(c-p_{n}\right) \beta+c\right) t-2 e \alpha \gamma(\alpha-1)$

is

$$
\Delta=\left((-\beta-1) c+k e+\beta p_{n}+p_{n} \alpha\right)^{2}+4 e^{2}(1+\beta) t^{2} \alpha \gamma(\alpha-1) .
$$

$$
\hat{\gamma}=-\frac{\left((-\beta-1) c+k e+\beta p_{n}+p_{n} \alpha\right)^{2}}{4 e^{2}(1+\beta) t^{2} \alpha(\alpha-1)} .
$$

Review we have $(\alpha+\beta) p_{n}+k e-(1+\beta)(t e+c)>0$; therefore we can find that

$$
t_{m}=\frac{2 \sqrt{-(1+\beta) \alpha \gamma(\alpha-1)}}{1+\beta} .
$$

Substituting it into above quadratic function:

We have a threshold

$$
\frac{2 \sqrt{\gamma}\left(-p_{n} \alpha-k e+\left(c-p_{n}\right) \beta+c\right) \sqrt{-(1+\beta) \alpha(\alpha-1)}-4 e \alpha \gamma(\alpha-1)(1+\beta)}{1+\beta} .
$$

And we have a same threshold:

$$
\widehat{\gamma}=-\frac{\left((-\beta-1) c+k e+\beta p_{n}+p_{n} \alpha\right)^{2}}{4 e^{2}(1+\beta) t^{2} \alpha(\alpha-1)} .
$$

It could be found that $(\partial p / \partial t)>0$ because $\Delta<0$ when $\gamma<\widehat{\gamma}$. And when $\gamma>\hat{\gamma}$, we have another threshold $\hat{t}$ and $\partial p /\left.\partial t\right|_{t=\hat{t}}=0$ because $\Delta>0$ and $\partial p /\left.\partial t\right|_{t_{m}}<0$. Therefore, when $\gamma>\hat{\gamma}$ and $t>\hat{t}, p$ is decreasing in $t$. And when $\gamma>\hat{\gamma}$ and $t<\hat{t}$, $p$ is increasing in $t$. 


\section{Proof of Proposition 2}

(1) Let $R=t(e-g) q$ denote total carbon tax, and the first derivative of $R$ in $t$ is

$\frac{\partial R}{\partial t}=\frac{2 \gamma\left(A_{2} t^{2}+B_{2} t+c\right)\left(A_{3} t^{2}+B_{3} t+c\right)}{\left(4 \gamma \alpha(1-\alpha)-t^{2}(1+\beta)\right)^{3}}$.

Among them

$$
\begin{gathered}
\left\{\begin{array}{l}
A_{2}=\frac{(1+\beta) e}{2}>0, \\
B_{2}=-\left((\alpha+\beta) p_{n}+k e-(1+\beta) c\right)<0, \\
C_{2}=2 \gamma e \alpha(1-\alpha)>0,
\end{array}\right. \\
\left\{\begin{array}{l}
A_{3}=\left((\alpha+\beta) p_{n}+k e-(1+\beta) c\right)(1+\beta)>0, \\
B_{3}=-8 \gamma e \alpha(1-\alpha)(1+\beta)<0, \\
C_{3}=4 \gamma \alpha(1-\alpha)\left((\alpha+\beta) p_{n}+k e-(1+\beta) c\right)>0 .
\end{array}\right.
\end{gathered}
$$

Let $\Phi=A_{2} t^{2}+B_{2} t+C_{2}$ and $\Psi=A_{3} t^{2}+B_{3} t+C_{3}$, and we can find that $\partial R / \partial t$ and $\Phi \times \Psi$ have a same sign. By solving $\Delta_{1}$ and $\Delta_{2}$, a threshold is

$$
\widehat{\gamma}_{3}=\frac{\left((\alpha+\beta) p_{n}+k e-(1+\beta) c\right)^{2}}{4 e^{2} \alpha(1-\alpha)(1+\beta)} .
$$

There are two positive real numbers of solutions for $\Phi$ if $\gamma<\widehat{\gamma}_{3}$, and let $0<t_{a}<t_{b}$ denote it. Similarly, let $0<t_{c}<t_{d}$ denote the solutions for $\Psi$ if $\gamma>\widehat{\gamma}_{3}$. Review we have $4 \alpha \gamma(1-\alpha)-(1+\beta) t^{2}>0$, therefore let $t_{m}=\sqrt{4 \gamma \alpha(1-a) / 1+\beta}$. Substituting $t_{m}$ into $\Phi$ and $\Psi$ :

$$
\left\{\begin{array}{l}
\left.\Phi\right|_{t_{m}}=-2 \sqrt{\frac{\gamma \alpha(1-\alpha)}{1+\beta}}\left((\alpha+\beta) p_{n}+k e-(1+\beta) c\right)+4 e \gamma \alpha(1-\alpha), \\
\left.\Psi\right|_{t_{m}}=-8 \gamma \alpha(1-\alpha)\left(2(1+\beta) e \sqrt{\frac{\alpha(1-\alpha)}{1+\beta}} \gamma-\left((\alpha+\beta) p_{n}+k e-(1+\beta) c\right)\right) .
\end{array}\right.
$$

If $\gamma<\widehat{\gamma}_{3},\left.\Phi\right|_{t_{m}}<0$, and $\left.\Psi\right|_{t_{m}}>0$, then $\partial R /\left.\partial t\right|_{t_{m}}<0$; If $\gamma>\widehat{\gamma}_{3},\left.\Phi\right|_{t_{m}}>0$, and $\left.\Psi\right|_{t_{m}}<0$, then $\partial R /\left.\partial t\right|_{t_{m}}<0$. Therefore, we have $t_{m} \in\left(t_{a}, t_{b}\right)$ or $t_{m} \in\left(t_{c}, t_{d}\right)$. Furthermore, $R=t(e-g) q$ is maximized when $t=t_{a}$ if $\gamma<\widehat{\gamma}_{3} ; R=$ $t(e-g) q$ is maximized when $t=t_{c}$ if $\gamma>\widehat{\gamma}_{3}$. Totally, we have

$$
t^{*}=\left\{\begin{array}{l}
t_{a}, \gamma<\widehat{\gamma}_{3} \\
t_{c}, \gamma>\widehat{\gamma}_{3}
\end{array}\right.
$$

(2) Review Proposition 1. If $\gamma>\widehat{\gamma}_{1}, g$ is maximized when $t^{*}=\widehat{t}_{1}$. If $\gamma<\widehat{\gamma}_{1}, g$ is maximized when $t^{*}=t_{m}$.

When $t>\widehat{t}_{1}, \widehat{\gamma}_{1}>\widehat{\gamma}_{5}$. And $\widehat{\gamma}_{1}<0<\widehat{\gamma}_{5}$ if $t<\widehat{t}_{1}$. Substituting $\widehat{t}_{1}$ into $\Phi$ :

$\Phi \vdash_{t_{1}}=-\frac{3\left((\alpha+\beta) p_{n}+k e-(1+\beta) c\right)^{2}}{8 e(1+\beta)}+2 e \gamma \alpha(1-\alpha)$.

A threshold is $\widehat{\gamma}_{4}=(3 / 4) \widehat{\gamma}_{3}$. Therefore, we have (i) when $0<\gamma<\widehat{\gamma}_{4}, t^{*}=t_{a}$ because of $\Phi t_{t_{1}}<0$ and $\widehat{t}_{1}>t_{a}$; (ii) when $\widehat{\gamma}_{4}<\gamma<\widehat{\gamma}_{3}, t^{*}=t_{a}$ because of $\widehat{t}_{1}<t_{a}$; (iii) $t^{*}=$ $t_{c}$ when $\widehat{\gamma}_{3}<\gamma<\widehat{\gamma}_{1}$; and (iv) $t^{*}=t_{c}$ when $\widehat{\gamma}_{1}<\gamma$. The result is obtained by solving $\Phi$ and $\Psi$.

\section{Proof of Theorem 2}

Similar to Appendix A. The retailer problem is addressed first, and we have

$$
p=\frac{\alpha \eta p_{n}+\beta \eta p_{n}+\eta k g+\beta w+w}{2 \eta(\beta+1)} .
$$

Then, substituting $p$ into the manufacturer's profit function. Solving the optimal $w$ and $g$ simultaneously yields

$$
\left\{\begin{array}{l}
w=\frac{\left(\alpha \eta p_{n}+\beta e t+\beta \eta p_{n}-\beta g t+e \eta k+c \beta+e t-g t+c\right) \eta}{(1+\eta)(\beta+1)}, \\
g=-\frac{\left(\alpha \eta p_{n}+\beta \eta p_{n}+e \eta k-\beta w-w\right) t}{2(\alpha-1) \gamma \alpha \eta} .
\end{array}\right.
$$


By solving the equation above, we have

$$
\begin{aligned}
& \left\{\begin{array}{l}
w=\frac{2 \gamma p_{n} \alpha^{3}+2 A_{1} \gamma \alpha^{2}+B_{1} \alpha+t^{2}(1+\beta)\left(\beta p_{n}+k e\right)}{(1+\beta)\left(t^{2}(1+\beta)-(1+\eta) \gamma \alpha(1-\alpha)\right)} \\
g=\frac{t\left(-\alpha p_{n}+e t(\beta+1)+\left(c-p_{n}\right) \beta-k e+c\right)}{t^{2}(1+\beta)-(1+\eta) \gamma \alpha(1-\alpha)} \\
p=\frac{(2 \eta+1) \gamma p_{n} \alpha^{3}+A_{2} \gamma \alpha^{2}+B_{2} \alpha+t^{2}(1+\beta)\left(\beta p_{n}+k e\right)}{(1+\beta)\left(t^{2}(1+\beta)-(1+\eta) \gamma \alpha(1-\alpha)\right)} \\
\left\{\begin{array}{l}
A_{1}=\left(e t+\eta p_{n}+c\right) \beta+e t+\left(k e-p_{n}\right) \eta+c, \\
A_{2}=\left((2 \eta+1) p_{n}+e t+c\right) \beta+(-2 \eta-1) p_{n}+e t+(2 \eta k+k) e+c \\
B_{2}=\left(\left((-2 \eta-1) p_{n}-e t-c\right) \beta-e t+(-2 \eta k-k) e-c\right) \gamma+t^{2} p_{n}(\beta+1) .
\end{array}\right.
\end{array}\right. \\
& \left\{\begin{array}{l}
B_{1}=\left(\left(-2 e t-2 \eta p_{n}-2 c\right) \beta-2 e \eta k-2 e t-2 c\right) \gamma+t^{2} p_{n}(\beta+1) \\
\{
\end{array}\right.
\end{aligned}
$$

Note that we have $-\alpha p_{n}+e t(\beta+1)+\left(c-p_{n}\right) \beta-k e+$ $c<0$. The concavity condition is $(1+\beta)\left(t^{2}(1+\beta)-(1+\right.$

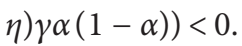

Substituting solutions into the profit function, we have

$$
\left\{\begin{array}{l}
\pi_{m}=-\frac{\left(\left(t e+c-p_{n}\right) \beta+(-k+t) e-\alpha p_{n}+c\right)^{2} \gamma}{2\left(t^{2} \beta+t^{2}+4(-1+\alpha) \gamma \alpha\right)(\beta+1)} \\
\pi_{r}=-\frac{\left(\left(t e+c-p_{n}\right) \beta+(-k+t) e-\alpha p_{n}+c\right)^{2}(-1+\alpha) \alpha \gamma^{2}}{\left(4 \alpha^{2} \gamma-4 \alpha \gamma+(\beta+1) t^{2}\right)^{2}(\beta+1)}
\end{array}\right.
$$

\section{E. Proof of Proposition 3}

$$
\left\{\begin{array}{l}
\pi_{M}=\frac{\left((\alpha+\beta) p_{n}+k e-(1+\beta) c\right)^{2} \gamma}{2(1+\beta)\left(4 \gamma \alpha(1-\alpha)-(1+\beta) t^{2}\right)^{2}} \\
\pi_{M}^{C}=\frac{\left((\alpha+\beta) p_{n}+k e-(1+\beta) c\right)^{2} \gamma}{2(1+\beta)\left(2(1+\eta) \gamma \alpha(1-\alpha)-(1+\beta) t^{2}\right)^{2}}
\end{array}\right.
$$

By comparing the profits of two partners change after the revenue-sharing contract introduced, we found that the manufacturer always benefits from cooperation:

$$
\left\{\begin{array}{l}
\pi_{R}=\frac{\gamma^{2} \alpha(1-\alpha)\left((\alpha+\beta) p_{n}+k e-(1+\beta)(t e+c)\right)^{2}}{(1+\beta)\left(4 \gamma \alpha(1-\alpha)-(1+\beta) t^{2}\right)^{2}}, \\
\pi_{R}^{C}=\frac{\eta \gamma^{2} \alpha(1-\alpha)\left((\alpha+\beta) p_{n}+k e-(1+\beta)(t e+c)\right)^{2}}{(1+\beta)\left(2(1+\eta) \gamma \alpha(1-\alpha)-(1+\beta) t^{2}\right)^{2}} .
\end{array}\right.
$$

A threshold is

$$
\eta_{1}=\left(\frac{2 \gamma \alpha(1-\alpha)-(1+\beta) t^{2}}{2 \gamma \alpha(1-\alpha)}\right)^{2} .
$$

When $\eta$ is in the region $\delta=\left(\eta_{1}, 1\right)$, the retailer will accept cooperation. And the first derivative of $\eta_{1}$ in $t$ is

$$
\frac{\partial \eta_{1}}{\partial t}=\frac{\left(2 \alpha^{2} \gamma-2 \alpha \gamma+t^{2}(\beta+1)\right) t(\beta+1)}{\alpha^{2} \gamma^{2}(-1+\alpha)^{2}}<0 .
$$

Therefore, $\eta_{1}$ is decreasing in $t$. That means the region $\delta=\left(\eta_{1}, 1\right)$ is expanding when tax rises. And the revenuesharing contract is accepted easily than before.

\section{F. Proof of Proposition 4}

We consider a simple function $\left(\lambda_{r} / \lambda_{m}\right)$ to decide the practical $\eta$, where $\lambda_{m} \in(0.5,1)$ and $\lambda_{r}=1-\lambda_{m}$. Given the 
carbon tax $t^{*}$, we have a region $\delta=\left(\eta\left(t^{*}\right), 1\right)$ of cooperation. It is clear that the gap of strength between two partitions in the supply chain is a crucial factor in cooperation. By comparing practice $\eta$, decided by strength, and $\eta\left(t^{*}\right)$, decided by the carbon tax, we have

$$
\frac{1}{\lambda_{m}}-1=\frac{\left(2 \alpha^{2} \gamma-2 \alpha \gamma+t^{2}(\beta+1)\right)^{2}}{4 \alpha^{2} \gamma^{2}(-1+\alpha)^{2}} .
$$

A threshold is

$$
\widehat{\lambda}_{1}=\frac{4 \alpha^{2} \gamma^{2}(-1+\alpha)^{2}}{8 \alpha^{4} \gamma^{2}-16 \alpha^{3} \gamma^{2}+4\left(2 \gamma+t^{2}(\beta+1)\right) \gamma \alpha^{2}-4 t^{2} \gamma(\beta+1) \alpha+t^{4}(\beta+1)^{2}}
$$

When $0.5<\lambda_{m}<\hat{\lambda}_{1}$, the practical $\eta$ is in the region $\delta=\left(\eta\left(t^{*}\right), 1\right)$; therefore, the cooperation is achieved facing the optimal carbon tax.

However, the practical $\eta$ is out of the range $\delta=\left(\eta\left(t^{*}\right), 1\right)$ when $\hat{\lambda}_{1}<\lambda_{m}$. Review previous result, the region $\delta=\left(\eta_{1}, 1\right)$ is expanding when tax rises. Therefore, there exists a possibility that the government increasing carbon tax to coordinate the supply chain. We assume a realistic thing: the government is willing to boost the greenness of the product even reducing part of the revenue from the carbon tax.

Based on it, the carbon up to $\hat{t}_{1}$ which means the greenness is maximized. Therefore, The cooperation is achieved when $\gamma<\widehat{\gamma}_{1}$ because the greenness is decreasing in the carbon tax when $\widehat{\gamma}_{1}<\gamma$. Then we have the second threshold:

$$
\widehat{\lambda}_{2}=\frac{1}{\eta_{1}\left(\widehat{t}_{1}\right)+1} \text {. }
$$

The cooperation could not be achieved when $\lambda_{m}>\hat{\lambda}_{2}$.

The conclusion is as follows: (1) Coordination would be achieved when the manufacturer is democratic (i.e., $0.5<\lambda_{m}<\hat{\lambda}_{1}$ ). (2) Coordination could be achieved but part of the total tax will lose if development cost is lower when the manufacturer is moderate (i.e., $\widehat{\lambda}_{1}<\lambda_{m}<\widehat{\lambda}_{2}$ ). (3) The cooperation could not be achieved if the manufacturer is a dictator (i.e., $\lambda_{m}>\widehat{\lambda}_{2}$ ).

\section{G. Proof of Proposition 5}

The first derivative of $\eta_{1}$ in $\beta$ is

$$
\frac{\partial \eta_{1}}{\partial t}=\frac{\left(2 \alpha^{2} \gamma-2 \alpha \gamma+t^{2}(\beta+1)\right) t^{2}}{2 \alpha^{2} \gamma^{2}(-1+\alpha)^{2}}<0
$$

Similarly, $\eta_{1}$ is decreasing in $\beta$. That means the region $\delta=\left(\eta_{1}, 1\right)$ is expanding when $\beta$ rises.

And it is apparent that $\eta_{1}=\left(2 \gamma \alpha(1-\alpha)-(1+\beta) t^{2} /\right.$ $2 \gamma \alpha(1-\alpha))^{2}$ is independent with $k$.

\section{Data Availability}

The data used to support the findings of this study are available from the corresponding author upon request.

\section{Conflicts of Interest}

The authors declare that there are no conflicts of interest regarding the publication of this paper.

\section{Acknowledgments}

This research was supported by the National Natural Science Foundation of China (no. 71761015) and the Science and Technology Research Project of Jiangxi Education Department of China (no. GJJ150475).

\section{References}

[1] Y. Li, M. K. Lim, J. Hu, and M.-L. Tseng, "Investigating the effect of carbon tax and carbon quota policy to achieve low carbon logistics operations," Resources, Conservation and Recycling, vol. 154, p. 104535, 2020.

[2] M. Abedi-Varaki, "Study of carbon dioxide gas treatment based on equations of kinetics in plasma discharge reactor," Modern Physics Letters B, vol. 31, no. 22, p. 1750210, 2017.

[3] S. Meng, M. Siriwardana, and J. McNeill, "The environmental and economic impact of the carbon tax in Australia," Environmental and Resource Economics, vol. 54, no. 3, pp. 313332, 2013.

[4] Y. Chen and C. L. Tseng, "Inducing clean technology in the electricity sector: tradable permits or carbon tax policies?" The Energy Journal, vol. 32, no. 3, 2011.

[5] H.-B. Duan, L. Zhu, and Y. Fan, "Optimal carbon taxes in carbon-constrained China: a logistic-induced energy economic hybrid model," Energy, vol. 69, pp. 345-356, 2014.

[6] C. Lu, Q. Tong, and X. Liu, "The impacts of carbon tax and complementary policies on Chinese economy," Energy Policy, vol. 38, no. 11, pp. 7278-7285, 2010.

[7] K. Cao, B. Xu, and J. Wang, "Optimal trade-in and warranty period strategies for new and remanufactured products under carbon tax policy," International Journal of Production Research, vol. 58, no. 1, pp. 180-199, 2020.

[8] P. He, W. Zhang, X. Xu, and Y. Bian, "Production lot-sizing and carbon emissions under cap-and-trade and carbon tax regulations," Journal of Cleaner Production, vol. 103, pp. 241-248, 2015.

[9] X. Xu, X. Xu, and P. He, "Joint production and pricing decisions for multiple products with cap-and-trade and carbon tax regulations," Journal of Cleaner Production, vol. 112, pp. 4093-4106, 2016. 
[10] Q. Li, X. Guan, T. Shi, and W. Jiao, "Green product design with competition and fairness concerns in the circular economy era," International Journal of Production Research, vol. 58, no. 1, pp. 165-179, 2020.

[11] A. Ranjan and J. K. Jha, "Pricing and coordination strategies of a dual-channel supply chain considering green quality and sales effort," Journal of Cleaner Production, vol. 218, pp. 409-424, 2019.

[12] S. Benjaafar, Y. Li, and M. Daskin, "Carbon footprint and the management of supply chains: insights from simple models," IEEE Transactions on Automation Science and Engineering, vol. 10, no. 1, pp. 99-116, 2012.

[13] X. Yin, X. Chen, X. Xu, and L. Zhang, "Tax or subsidy? Optimal carbon emission policy: a supply chain perspective," Sustainability, vol. 12, no. 4, p. 1548, 2020.

[14] B. B. Schlegelmilch, G. M. Bohlen, and A. Diamantopoulos, "The link between green purchasing decisions and measures of environmental consciousness," European Journal of Marketing, vol. 30, no. 5, pp. 35-55, 1996.

[15] M. S. Hopkins, "What the 'green' consumer wants," MIT Sloan Management Review, vol. 50, no. 4, pp. 87-89, 2009.

[16] G. Kalyanaram and R. S. Winer, "Empirical generalizations from reference price research," Marketing Science, vol. 14, no. 3, pp. G161-G169, 1995.

[17] E. A. Greenleaf, "The impact of reference price effects on the profitability of price promotions," Marketing Science, vol. 14, no. 1, pp. 82-104, 1995.

[18] N. M. Modak, D. K. Ghosh, S. Panda, and S. S. Sana, "Managing green house gas emission cost and pricing policies in a two-echelon supply chain," CIRP Journal of Manufacturing Science and Technology, vol. 20, pp. 1-11, 2018.

[19] P. Sinclair, "High does nothing and rising is worse: carbon taxes should keep declining to cut harmful emissions," The Manchester School, vol. 60, no. 1, pp. 41-52, 1992.

[20] G. M. Grossman and A. B. Krueger, "Economic growth and the environment," The Quarterly Journal of Economics, vol. 110, no. 2, pp. 353-377, 1995.

[21] N. M. Modak and P. Kelle, "Using social work donation as a tool of corporate social responsibility in a closed-loop supply chain considering carbon emissions tax and demand uncertainty," Journal of the Operational Research Society, pp. 1-17, 2019.

[22] A. Ulph and D. Ulph, "The optimal time path of a carbon tax," Oxford Economic Papers, vol. 46, no. S1, pp. 857-868, 1994.

[23] M. Hoel and S. Kverndokk, "Depletion of fossil fuels and the impact of global warming," Resource and Energy Economics, vol. 18, no. 2, pp. 115-136, 1996.

[24] Y. H. Farzin and O. Tahvonen, "Global carbon cycle and the optimal time path of a carbon tax," Oxford Economic Papers, vol. 48, no. 4, pp. 515-536, 1996.

[25] V. Bosetti, C. Carraro, R. Duval, and M. Tavoni, "What should we expect from innovation? A model-based assessment of the environmental and mitigation cost implications of climaterelated R\&D," Energy Economics, vol. 33, no. 6, pp. 1313-1320, 2011.

[26] M. Hariga, R. As'ad, and A. Shamayleh, "Integrated economic and environmental models for a multi stage cold supply chain under carbon tax regulation," Journal of Cleaner Production, vol. 166, pp. 1357-1371, 2017.

[27] N. Turken, J. Carrillo, and V. Verter, "Facility location and capacity acquisition under carbon tax and emissions limits: to centralize or to decentralize?" International Journal of Production Economics, vol. 187, pp. 126-141, 2017.
[28] W. Yu and R. Han, "Coordinating a two-echelon supply chain under carbon tax," Sustainability, vol. 9, no. 12, p. 2360, 2017.

[29] S. Sinha and N. M. Modak, "An EPQ model in the perspective of carbon emission reduction," International Journal of Mathematics in Operational Research, vol. 14, no. 3, pp. 338-358, 2019.

[30] H. Zhang, P. Li, H. Zheng, and Y. Zhang, "Impact of carbon tax on enterprise operation and production strategy for lowcarbon products in a co-opetition supply chain," Journal of Cleaner Production, Article ID 125058, 2020.

[31] X. Chen, H. Yang, X. Wang et al., "Optimal carbon tax design for achieving low carbon supply chains," Annals of Operations Research, pp. 1-28, 2020.

[32] D. Kahneman and A. Tversky, "Prospect theory: an analysis of decision under risk," Handbook of the Fundamentals of Financial Decision Making: Part I, pp. 99-127, The Econometric Society, Cleveland, OH, USA, 2013.

[33] W. Kim and M. Kim, "Reference quality-based competitive market structure for innovation driven markets," International Journal of Research in Marketing, vol. 32, no. 3, pp. 284-296, 2015.

[34] I. Popescu and Y. Wu, "Dynamic pricing strategies with reference effects," Operations Research, vol. 55, no. 3, pp. 413-429, 2007.

[35] P. K. Kopalle, P. K. Kannan, L. B. Boldt, and N. Arora, "The impact of household level heterogeneity in reference price effects on optimal retailer pricing policies," Journal of Retailing, vol. 88, no. 1, pp. 102-114, 2012.

[36] T.-P. Hsieh and C.-Y. Dye, "Optimal dynamic pricing for deteriorating items with reference price effects when inventories stimulate demand," European Journal of Operational Research, vol. 262, no. 1, pp. 136-150, 2017.

[37] X. Chen, Z.-Y. Hu, and Y.-H. Zhang, "Dynamic pricing with stochastic reference price effect," Journal of the Operations Research Society of China, vol. 7, no. 1, pp. 107-125, 2019.

[38] X. Chen, P. Hu, S. Shum, and Y. Zhang, "Dynamic stochastic inventory management with reference price effects," Operations Research, vol. 64, no. 6, pp. 1529-1536, 2016.

[39] L. Zhang, H. Zhou, Y. Liu, and R. Lu, "Optimal environmental quality and price with consumer environmental awareness and retailer's fairness concerns in supply chain," Journal of Cleaner Production, vol. 213, pp. 1063-1079, 2019.

[40] C. Chen, "Design for the environment: a quality-based model for green product development," Management Science, vol. 47, no. 2, pp. 250-263, 2001.

[41] K. Chitra, "In search of the green consumers: a perceptual study," Journal of Services Research, vol. 7, no. 1, 2007.

[42] Z. Liu, T. D. Anderson, and J. M. Cruz, "Consumer environmental awareness and competition in two-stage supply chains," European Journal of Operational Research, vol. 218, no. 3, pp. 602-613, 2012.

[43] B. Li, Y. Wang, and Z. Wang, "Managing a closed-loop supply chain with take-back legislation and consumer preference for green design," Journal of Cleaner Production, Article ID 124481, 2020.

[44] J. Rantanen, D. B. Grant, and W. Piotrowicz, "Investigating supply chain cooperation in Finnish grocery retail," Research Journal of the University of Gdańsk: Transport Economics and Logistics, vol. 71, pp. 19-34, 2017.

[45] G. P. Cachon and M. A. Lariviere, "Supply chain coordination with revenue-sharing contracts: strengths and limitations," Management Science, vol. 51, no. 1, pp. 30-44, 2005.

[46] G. Xu, B. Dan, X. Zhang, and C. Liu, "Coordinating a dualchannel supply chain with risk-averse under a two-way 
revenue sharing contract," International Journal of Production Economics, vol. 147, pp. 171-179, 2014.

[47] Z. Shi, N. Wang, T. Jia et al., "Reverse revenue sharing contract versus two-part tariff contract under a closed-loop supply chain system," Mathematical Problems in Engineering, vol. 2016, Article ID 5464570, 15 pages, 2016.

[48] S. Panda, N. M. Modak, and L. E. Cárdenas-Barrón, "Coordinating a socially responsible closed-loop supply chain with product recycling," International Journal of Production Economics, vol. 188, pp. 11-21, 2017.

[49] N. M. Modak, N. Modak, S. Panda, and S. S. Sana, “Analyzing structure of two-echelon closed-loop supply chain for pricing, quality and recycling management," Journal of Cleaner Production, vol. 171, pp. 512-528, 2018.

[50] Q. P. Wang and D. Z. Zhao, "Revenue-sharing contract of supply chain based on consumer's preference for low carbon products," Chinese Journal of Management Science, vol. 22, no. 9, pp. 106-113, 2014.

[51] B. Yu, J. Wang, X. Lu, and H. Yang, "Collaboration in a lowcarbon supply chain with reference emission and cost learning effects: cost sharing versus revenue sharing strategies," Journal of Cleaner Production, vol. 250, Article ID 119460, 2020.

[52] J. Cao, X. Zhang, and G. Zhou, "Supply chain coordination with revenue-sharing contracts considering carbon emissions and governmental policy making," Environmental Progress \& Sustainable Energy, vol. 35, no. 2, pp. 479-488, 2016.

[53] X. Xu, P. He, H. Xu, and Q. Zhang, "Supply chain coordination with green technology under cap-and-trade regulation," International Journal of Production Economics, vol. 183, pp. 433-442, 2017.

[54] N. M. Modak, S. Sinha, S. Panda et al., "Analyzing a socially responsible closed-loop distribution channel with recycling facility," SN Applied Sciences, vol. 1, no. 10, p. 1189, 2019.

[55] D. Feng, L. Ma, Y. Ding, G. Wu, and Y. Zhang, "Decisions of the dual-channel supply chain under double policy considering remanufacturing," International Journal of Environmental Research and Public Health, vol. 16, no. 3, p. 465, 2019.

[56] I. Bellos, M. Ferguson, and L. B. Toktay, "The car sharing economy: interaction of business model choice and product line design," Manufacturing \& Service Operations Management, vol. 19, no. 2, pp. 185-201, 2017.

[57] G. Ferrer and J. M. Swaminathan, "Managing new and remanufactured products," Management Science, vol. 52, no. 1, pp. 15-26, 2006.

[58] B. Yalabik and R. J. Fairchild, "Customer, regulatory, and competitive pressure as drivers of environmental innovation," International Journal of Production Economics, vol. 131, no. 2, pp. 519-527, 2011.

[59] L. Cui, S. Guo, and H. Zhang, "Coordinating a green agri-food supply chain with revenue-sharing contracts considering retailers' green marketing efforts," Sustainability, vol. 12, no. 4, p. 1289, 2020.

[60] J. Heydari, K. Govindan, and A. Aslani, "Pricing and greening decisions in a three-tier dual channel supply chain," International Journal of Production Economics, vol. 217, pp. 185196, 2019. 